\title{
Sugars take a central position in plant growth, development and, stress responses. A focus on apical dominance
}

\author{
Wim Van den Ende* \\ Laboratory of Molecular Plant Biology, Biology, Katholieke Universiteit Leuven, Leuven, Belgium \\ ${ }^{*}$ Correspondence: wim.vandenende@bio.kuleuven.be \\ Edited by: \\ Els J. M. Van Damme, Ghent University, Belgium \\ Reviewed by: \\ Sjef Smeekens, Utrecht University, Netherlands \\ Soulaiman Sakr, Agrocampus-ouest, France
}

Keywords: sugar signaling, apical dominance, auxin response, trehalose 6-phosphate, sucrose, phloem transport, hormone signaling

In plant glycobiology, free "metabolic" carbohydrates consist of small sugars (glucose, fructose, sucrose, trehalose), sucrose-derived oligosaccharides (fructans, Raffinose Family Oligosaccharides), starch and its breakdown products (Van den Ende, 2013). All these carbohydrates are directly or indirectly derived from photosynthesis. Plants typically accumulate higher carbohydrate levels as compared with other multicellular eukaryotes, especially when (milder) stresses compromise growth more than photosynthesis (Van den Ende and El-Esawe, in press).

In a historical perspective, the central role of sugars was already suggested many decades ago, with proposed roles in overall plant growth and development (Allsopp, 1954), disease susceptibility (Horsfall and Dimond, 1957), flowering (Kraus and Kraybill, 1918) and apical dominance (Loeb, 1924). The latter two processes were suggested to be regulated by the "nutrient diversion hypothesis" (Gregory and Veale, 1957; Corbesier et al., 1998). This theory, narrowed down to sugar nutrients, states that a minimal level of sugar assimilates needs to reach the apex (flowering) or lateral bud (removal of apical dominance) before floral transition or lateral bud outgrowth is initiated. The discovery that indole-3-acetic acid (IAA) repressed lateral bud outgrowth in decapitated shoots (Thimann, 1937) boosted plant hormone research at the expense of sugar-centered research. However, things changed when small sugars, similar to hormones, were considered as important signals in plants (Moore et al., 2003). Since then, a renewed and strongly increasing worldwide interest in sugar signaling, sensing and metabolism was noticed (Ruan, 2014; Smeekens and Hellmann, 2014).

Mason et al. (2014) focused on the underlying mechanisms involved during apical dominance in pea. The authors challenge a long-held dogma in plant physiology, proposing that sugar signals, and not IAA, initiates lateral bud outgrowth after apex decapitation. For decades, textbooks declare that phloemmediated IAA transport fluxes down the stem decrease after decapitation, relieving the IAA-mediated inhibition on bud outgrowth. However, the discovery that stem IAA cannot enter the bud, and the fact that IAA application on decapitated stems cannot always prevent bud burst, suggested that a positive signal could overrule IAA-mediated inhibitory effects (Mason et al., 2014).

Buds from the decapitated apex could be released starting from $2.5 \mathrm{~h}$ post-decapitation as shown by timelapse photography (Mason et al., 2014). Importantly, this was not accompanied by a measurable IAA depletion in the adjacent stem. However, a much slower bud release was reported before (Wardlaw and Mortimer, 1970). Mason et al. (2014) designed an elegant set of physiological experiments demonstrating that leaves are the source of a rapid decapitation induced signal that promotes bud release. They reasoned that sucrose could be a candidate for this signaling role. Subsequently, $\left[{ }^{11} \mathrm{C}\right]$ $\mathrm{CO}_{2}$ was fed to leaves and the movement of $\left[{ }^{11} \mathrm{C}\right]$ photo-assimilates was monitored along the stem. They found a speed of $150 \mathrm{~cm} \mathrm{~h}^{-1}$, which agreed with the timing of bud burst and phloem-mediated transport. Exogenous sucrose applications promoted bud burst. Moreover, in plants decapitated low on the stem, leaf removal caused a serious delay in bud release, and this could be rescued by feeding sucrose, but not sorbitol, via the petiole. Unfortunately, the sucrose-specific character of this response was not tested. Comparing glucose and sucrose responses could be informative to discriminate between glucose- or sucrose-mediated signaling events.

These data strongly suggest that a minimal threshold sucrose level is required to sustain lateral bud outgrowth. Initiation of bud outgrowth would not make much sense if not enough $\mathrm{C}$ would be available to sustain the later stages of bud growth. However, this leaves us with a remaining question: is there still room for hormone signaling events in this process?

I speculate that the answer on this question is "yes." Internal sugar/IAA ratios within lateral buds or within the adjacent stem may be somehow integrated prior to lateral bud outgrowth initiation. In my opinion further studies should answer the following crucial questions (i) Are increased sugar levels associated with changed hormone levels in buds and how does this change over time? (ii) Do bud IAA levels depend on IAA biosynthesis from tryptophan within the bud, or is indol-3-aldehyde, a phloem-mobile lateral bud inhibitor (Nakajima et al., 2002), involved via a 
mechanism that perhaps depends on sugar signaling? If so, can the presence of indol3-aldehyde in the phloem sap be confirmed? (iii) Alternatively, could phloem residing Aux/IAA transcripts, involved in the regulation of auxin signaling, enter the bud followed by differential translation depending on the actual sugar status? Such transcripts may be important, since their upregulation in the phloem influences both root and shoot branching, as well as overall IAA sensitivity (Golan et al., 2013). Some of these views fit with emerging evidence that sugars can control auxin levels in plants (LeClere et al., 2010; Sairanen et al., 2012). Hexokinase (HXK) mediated sugar signaling may be central in such processes, since AtHXK1 overexpressors relieved their apical dominance (Kelly et al., 2012). This was associated with lowered expression levels of genes that encode crucial players in auxin signaling, suggesting that glucose signals control downstream auxin signaling in Arabidopsis (Kelly et al., 2012).

It cannot be excluded that light dependent signaling mechanisms, or any other positive factors, may have remained undetected in the pea apical dominance paper (Mason et al., 2014). Moreover, these experiments should be repeated in an array of other plant species, before any general conclusions can be derived that would apply to all higher plants. GA, sugars and light play crucial roles during bud outgrowth in roses through increasing sugar demand, by upregulating the expression and activity of vacuolar invertases (Choubane et al., 2012; Rabot et al., 2012).

Despite these critical notes, it should be recognized that the paper of Mason et al. (2014) boosts further research in both hormone and sugar signaling communities, by stimulating hormone workers to consider sugars and vice-versa. So far, attempts to integrate sugar and hormone signaling events are rather scarce (Bolouri Moghaddam and Van den Ende, 2013). The putative importance of sugar signaling events in apical dominance ads to a list of other physiological processes that are believed to be controlled by sugars or their phosphorylated derivatives such as trehalose 6-phosphate (T6P), which has been suggested as an important indicator of the carbohydrate status in plants and negative regulator of SnRK1 (Zhang et al.,
2009). The latter is a central player in overall energy homeostasis (Baena-González et al., 2007) together with TOR kinase (Robaglia et al., 2012; Xiong et al., 2013). The T6P/SnRK1 module is involved in sugar signaling processes (Baena-González et al., 2007) together with sucrose-specific DELLA-mediated processes (Li et al., 2014) controlling, for example, anthocyanin accumulation as part of the plants defense response (Nakabayashi et al., 2014).

In line with the earlier ideas of Allsopp (1954), recent molecular and biochemical evidences revealed that sugars regulate the juvenile-to-adult phase transition by modulating miR156 expression, with possible involvement of HXK-mediated signaling (Duarte et al., 2013; Yang et al., 2013; Yu et al., 2013). Moreover, it was demonstrated that rhythmic, endogenous sugar signals, independently of light signals, entrain circadian rhythms by regulating the expression of circadian clock components (Haydon et al., 2013). Recent data strongly suggest that leaf diurnal starch dynamics (Graf and Smith, 2011) intimately connect with T6P levels (Martins et al., 2013). In line with the nutrient diversion hypothesis, it is proposed that plants sense the T6P status prior to the transition to flowering (Wahl et al., 2013). Photoperiod modification of starch homeostasis by CONSTANS, a stimulator of the FLOWERING LOCUS T, may be crucial for increasing the sugar mobilization demanded by the floral transition (OrtizMarchena et al., 2014). These observations urge further research into T6P levels, starch dynamics and SnRK1 activities in the context of apical dominance.

Clearly, we are only at the beginning of our understanding of the complexity of cellular sugar homeostasis, and deciphering how this exactly connects to hormonal regulatory mechanisms is an important challenge.

\section{ACKNOWLEDGMENT}

Wim Van den Ende is supported by funding from the FSR, Flanders.

\section{REFERENCES}

Allsopp, A. (1954). Juvenile stages of plants and the nutritional status of the shoot apex. Nature 173, 1032-1035. doi: 10.1038/1731032a0

Baena-González, E., Rolland, F., Thevelein, J. M., and Sheen, J. (2007). A central integrator of transcription networks in plant stress and energy signaling. Nature 448, 938-942. doi: 10.1038 /nature06069

Bolouri Moghaddam, M., and Van den Ende, W. (2013). Sugars, the clock and transition to flowering. Front. Plant Sci. 4:22. doi: 10.3389/fpls.2013.00022

Choubane, D., Rabot, A., Mortreau, E., Legourrierec, J., Peron, T., Foucher, F., et al. (2012). Photocontrol of bud burst involves gibberellin biosynthesis in Rosa sp. J. Plant Physiol. 169, 1271-1280. doi: 10.1016/j.jplph.2012.04.014

Corbesier, L., Lejeune, P., and Bernier, G. (1998). The role of carbohydrates in the induction of flowering in Arabidopsis thaliana: comparison between the wild-type and a starchless mutant. Planta 206, 131-137. doi: 10.1007/s004250050383

Duarte, G. T., Matiolli, C. C., Pant, B. D., Schlereth, A., Scheible, W.-F., Stitt, M. et al. (2013). Involvement of microRNA-related regulatory pathways in the glucose-mediated control of Arabidopsis early seedling development. J. Exp. Bot. 64, 4301-4312. doi: 10.1093/jxb/ert239

Golan, G., Betzer, R., and Wolf, S. (2013). Phloemspecific expression of a melon Aux/IAA in tomato plants alters auxin sensitivity and plant development. Front. Plant Sci. 4:329. doi: $10.3389 /$ fpls.2013.00329

Graf, A., and Smith, A. M. (2011). Starch and the clock: the dark side of plant productivity. Trends Plant Sci. 16, 169-175. doi: 10.1016/j.tplants.2010.12.003

Gregory, F. G., and Veale, J. A. (1957). A reassessment of the problem of apical dominance. Symp. Soc. Exp. Biol. 11, 1-20.

Haydon, M. J., Mielczarek, O., Robertson, F. C., Hubbard, K. E., and Webb, A. A. (2013). Photosynthetic entrainment of the Arabidopsis thaliana circadian clock. Nature 502, 689-692. doi: 10.1038 /nature 12603

Horsfall, J. G., and Dimond, A. E. (1957). Interactions of tissue sugar, growth substances, and disease susceptibility. Zeitschrift fur Pflanzen krankheiten und Pflanzenschutz 64, 415-421.

Kelly, G., David-Schwartz, R., Sade, N., Moshelion, M., Levi, A., Alchanatis, V., et al. (2012). The pitfalls of transgenic selection and new roles of AtHXK1: a high level of AtHXK1 expression uncouples hexokinase1-dependent sugar signaling from exogenous sugar. Plant Physiol. 159, 47-51. doi: 10.1104/pp.112.196105

Kraus, E. J., and Kraybill, H. R. (1918). Vegetation and Reproduction with Special Reference to the Tomato. Station bulletin (Oregon Agricultural Experiment Station). Corvallis, OR: Oregon Agricultural College Experiment Station.

LeClere, S., Schmelz, E. A., and Chourey, P. S. (2010). Sugar levels regulate tryptophan-dependent auxin biosynthesis in developing maize kernels. Plant Physiol. 153, 306-318. doi: 10.1104/pp.110. 155226

Li, Y., Van den Ende, W., and Rolland, F. (2014). Sucrose induction of anthocyanin biosynthesis is mediated by DELLA. Mol. Plant 7, 570-572. doi: $10.1093 / \mathrm{mp} / \mathrm{sst} 161$

Loeb, J. (1924). Regeneration from a Physic-Chemical Viewpoint. New York, NY: McGRaw-Hill.

Martins, M. C., Hejazi, M., Fettke, J., Steup, M., Feil, R., Krause, U., et al. (2013). Feedback inhibition 
of starch degradation in Arabidopsis leaves mediated by trehalose 6-phosphate. Plant Physiol. 163, 1142-1163. doi: 10.1104/pp.113.226787

Mason, M. G., Ross, J. J., Babst, B. A., Wienclaw, B. N., and Beveridge, C. A. (2014). Sugar demand, not auxin, is the initial regulator of apical dominance. Proc. Natl. Acad. Sci. U.S.A. 111, 6092-6097. doi: 10.1073/pnas.1322045111

Moore, B., Zhou, L., Rolland, F., Hall, Q., Cheng, W. H., Liu, Y. X., et al. (2003). Role of the Arabidopsis glucose sensor HXK1 in nutrient, light, and hormonal signalling. Science 300, 332-336. doi: 10.1126/science. 1080585

Nakabayashi, R., Yonekura Sakakibara, K., Urano, K., Suzuki, M., and Yamada, Y. (2014). Enhancement of oxidative and drought tolerance in Arabidopsis by overaccumulation of antioxidant flavonoids. Plant J. 77, 367-379. doi: 10.1111/tpj.12388

Nakajima, E., Nakano, H., Yamada, K., Shigemori, H., and Hasegawa, K. (2002). Isolation and identification of lateral bud growth inhibitor, indole3-aldehyde, involved in apical dominance of pea seedlings. Phytochemistry 61, 863-865. doi: 10.1016/S0031-9422(02)00400-4

Ortiz-Marchena, M. I., Albi, T., Lucas-Reina, E., Said, F. E., Romero-Campero, F. J., Cano, B., et al. (2014). Photoperiodic control of carbon distribution during the floral transition in Arabidopsis. Plant Cell 26, 565-584. doi: 10.1105/tpc.114.122721

Rabot, A., Henry, C., Ben Baaziz, K., Mortreau, E., Azri, W., Lothier, J., et al. (2012). Insight into the role of sugars in bud burst under light in the rose. Plant Cell Physiol. 53, 1068-1082. doi: $10.1093 / \mathrm{pcp} / \mathrm{pcs} 051$

Robaglia, C., Thomas, M., and Meyer, C. (2012). Sensing nutrient and energy status by SnRK1 and TOR kinases. Curr. Opin. Plant Biol. 15, 301-307. doi: 10.1016/j.pbi.2012.01.012
Ruan, Y.-L. (2014). Sucrose metabolism: gateway to diverse carbon use and sugar signaling. Annu. Rev. Plant Biol. 65, 26.1-26.35. doi: 10.1146/annurevarplant-050213-040251

Sairanen, I., Novák, O., Pencík, A., Ikeda, Y., Jones, B., Sandberg, G., et al. (2012). Soluble carbohydrates regulate auxin biosynthesis via PIF proteins in Arabidopsis. Plant Cell 24, 4907-4916. doi: 10.1105/tpc.112.104794

Smeekens, J., and Hellmann, H. A. (2014). Sugar sensing and signaling in plants. Front. Plant Sci. 5:113. doi: $10.3389 /$ fpls. 2014.00113

Thimann, K. V. (1937). On the nature of the inhibitions caused by auxin. Am. J. Bot. 24, 407-412. doi: $10.2307 / 2436422$

Van den Ende, W. (2013). Multifunctional fructans and raffinose family oligosaccharides. Front. Plant Sci. 4:247. doi: 10.3389/fpls.2013.00247

Van den Ende, W., and El-Esawe, S. (in press). Sucrose signaling pathways leading to fructan and anthocyanin accumulation: a dual function in abiotic and biotic stress responses? Environ. Exp. Bot. doi: 10.1016/j.envexpbot.2013.09.017

Wahl, V., Ponnu, J., Schlereth, A., Arrivault, S., Langenecker, T., Franke, A., et al. (2013). Regulation of flowering by trehalose-6-phosphate signaling in Arabidopsis thaliana. Science 339, 704-707. doi: 10.1126/science.1230406

Wardlaw, I. F., and Mortimer, D. C. (1970). Carbohydrate movement in pea plants in relation to axillary bud growth and vascular development. Can. J. Bot. 48, 229-237. doi: 10.1139/b70-035

Xiong, Y., McCormack, M., Li, L., Hall, Q., Xiang, C., and Sheen, J. (2013). Glucose-TOR signalling reprograms the transcriptome and activates meristems. Nature 496, 181-186. doi: 10.1038/nature12030

Yang, L., Xu, M., Koo, Y., He, J., and Poethig, R. S. (2013). Sugar promotes vegetative phase change in
Arabidopsis thaliana by repressing the expression of MIR156A and MIR156C. Elife 2:e00260. doi: 10.7554/eLife.00260

Yu, S., Cao, L., Zhou, C-M., Zhang, T-Q., Lian, H., Sun, Y., et al. (2013). Sugar is an endogenous cue for juvenile-to-adult phase transition in plants. Elife 2:e00269. doi: 10.7554/eLife. 00269

Zhang, Y., Primavesi, L. F., Jhurreea, D., Andralojc, P. J., Mitchell, R. A. C., Powers, S. J., et al. (2009). Inhibition of SNF1-related protein kinase 1 activity and regulation of metabolic pathways by trehalose-6-phosphate. Plant Physiol. 149, 1860-1871. doi: 10.1104/pp.108. 133934

Conflict of Interest Statement: The author declares that the research was conducted in the absence of any commercial or financial relationships that could be construed as a potential conflict of interest.

Received: 27 May 2014; accepted: 13 June 2014; published online: 30 June 2014.

Citation: Van den Ende W (2014) Sugars take a central position in plant growth, development and, stress responses. A focus on apical dominance. Front. Plant Sci. 5:313. doi: 10.3389/fpls.2014.00313

This article was submitted to Plant Physiology, a section of the journal Frontiers in Plant Science.

Copyright (C) 2014 Van den Ende. This is an openaccess article distributed under the terms of the Creative Commons Attribution License (CC BY). The use, distribution or reproduction in other forums is permitted, provided the original author(s) or licensor are credited and that the original publication in this journal is cited, in accordance with accepted academic practice. No use, distribution or reproduction is permitted which does not comply with these terms. 